\title{
Perioperative coronary artery spasm leading to myocardial ischaemia after vein graft surgery
}

\author{
BARTOLO ZINGONE, ALESSANDRO SALVI, BRUNO BRANCHINI \\ From the Departments of Cardiac Surgery and Cardiology, Ospedale Maggiore and University of Trieste Medical \\ School, Trieste, Italy
}

SUMMARY Coronary artery spasm has been recognised recently as a possible cause of perioperative myocardial ischaemia after coronary artery bypass grafting. We report on one case and review the published reports. We emphasise the clinical picture of the patient who is liable to have spasm and ${ }_{-}^{\supset}$ the necessity for a prompt diagnosis and correct treatment.

The incidence of perioperative myocardial infarction after coronary artery surgery has shown a progressive fall over the years. ${ }^{1-3}$ Cold cardioplegia is the single most important reason for this, but it cannot deal with every possible mechanism of perioperative myocardial ischaemia. Coronary artery spasm may indeed constitute such a mechanism, ${ }^{4-6}$ and its occurrence in a case in our department prompted this report.

\section{Case history}

A 42 year old man complained of exertional angina with decreasing threshold over the past six months; on occasion, chest pain occurred at rest. Angiography showed isolated, severe, proximal stenosis of the left anterior descending coronary artery, which persisted unchanged after $0.3 \mathrm{mg}$ glyceryl trinitrate sublingually.

The patient was discharged on oral nifedipine and isosorbide dinitrate, $60 \mathrm{mg}$ each daily, but was readmitted five days later complaining of severe angina on minimal effort and at rest, and we therefore decided to operate. Electrocardiograms showed either a normal pattern or anteroseptal ST and T wave ischaemic changes.

At operation the left anterior descending artery was uneventfully grafted with an autologous saphenous vein under hypothermic cardiopulmonary bypass and cardioplegia. The electrocardiogram in the recovery room was normal.

Five hours after operation the patient complained of acute ischaemic chest pain, and simultaneous ST segment depression was recorded from almost all peripheral and precordial leads. The pain resolved, but ST changes were still present after sublinguab glyceryl trinitrate. Sublingual nifedipine and isosor- $\omega$ bide, by hourly increments of 10 and $5 \mathrm{mg}$, respec응 tively, as well as intravenous glyceryl trinitrate up to $1 \mathrm{mg} / \mathrm{h}$, were not effective in preventing recurrence of chest pain, and the patient was therefore taken to the catheterisation laboratory three hours after the initia $B$ episode of angina. Selective angiography of the graf $\overrightarrow{\bar{S}}$ and the native coronary arteries was performed undeB continuous glyceryl trinitrate infusion at $1 \mathrm{mg} / \mathrm{h}$. The right coronary artery (Fig. 1a) and all branches of the left coronary artery appeared diffusely narrowed. The vein graft was patent despite a very poor run-off (Fig@ 1b). Glyceryl trinitrate, $1 \mathrm{mg}$, was then administeres into each coronary artery and into the graft; subse 3 . quent injections of contrast medium demonstrated the return of each vessel to its previous size, while lef5 anterior descending artery graft appeared satisfactory 6 (Fig. 2).

Total CK and MB peaked at 576 and 38 units? respectively, on the morning of the first postoperative day. The electrocardiogram returned to baselines without any further ST change, or pathological of waves.

After catheterisation, nitrates were continued at total daily dose of $306 \mathrm{mg}$ (through combined sublin gual, intravenous, and percutaneous routes) which was halved after one week. There were no furthe? episodes of angina.

Six weeks after operation the patient was readmito ted for elective stress testing, dynamic electrocardiog $\mathbb{D}_{0}$ raphy, and repeat angiography. All findings were्尺 normal, and the patency of the vein graft was confirmed. 

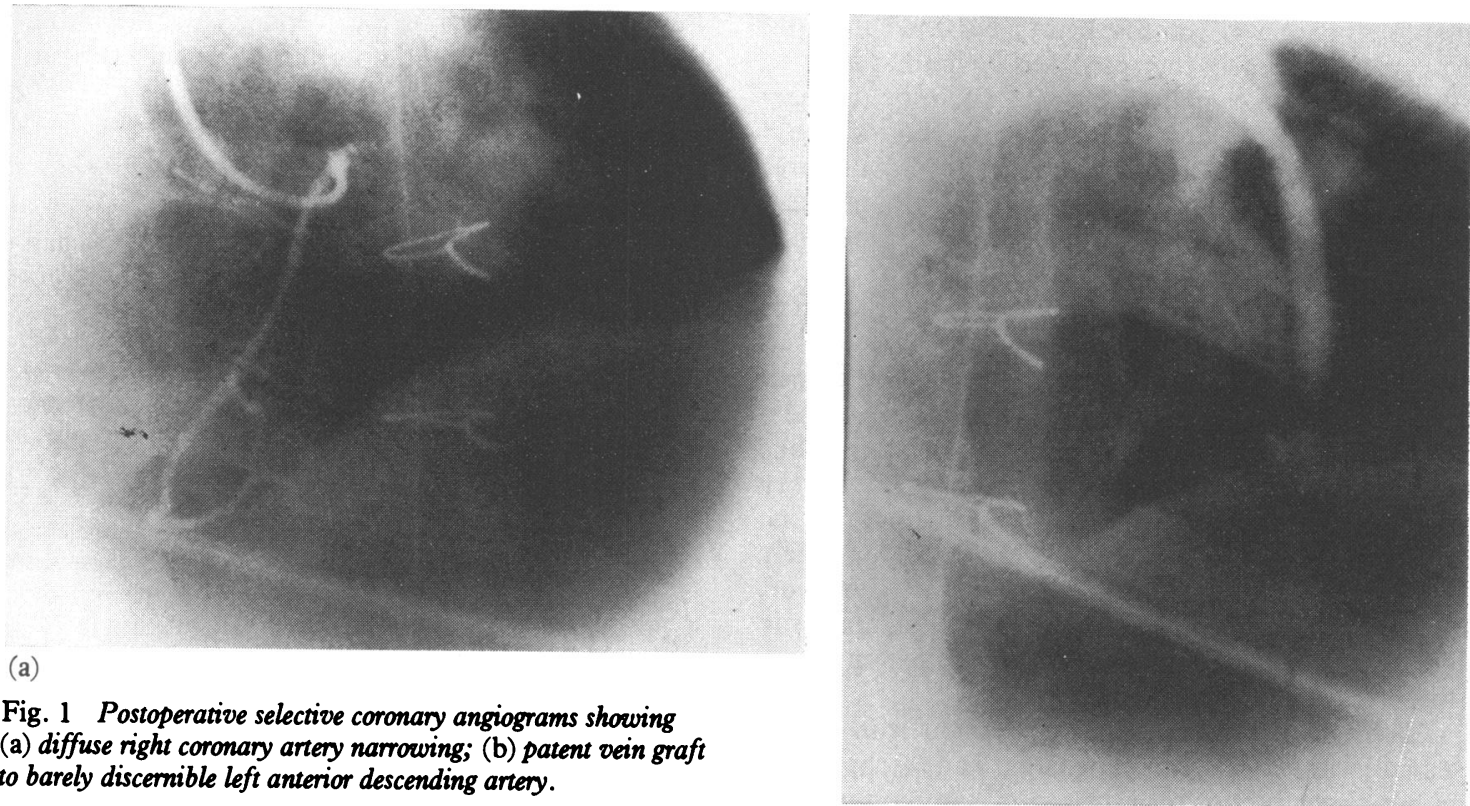

Fig. 1 Postoperative selective coronary angiograms showing (a) diffuse right coronary artery narrowing; (b) patent vein graft to barely discernible left anterior descending artery.

(b)
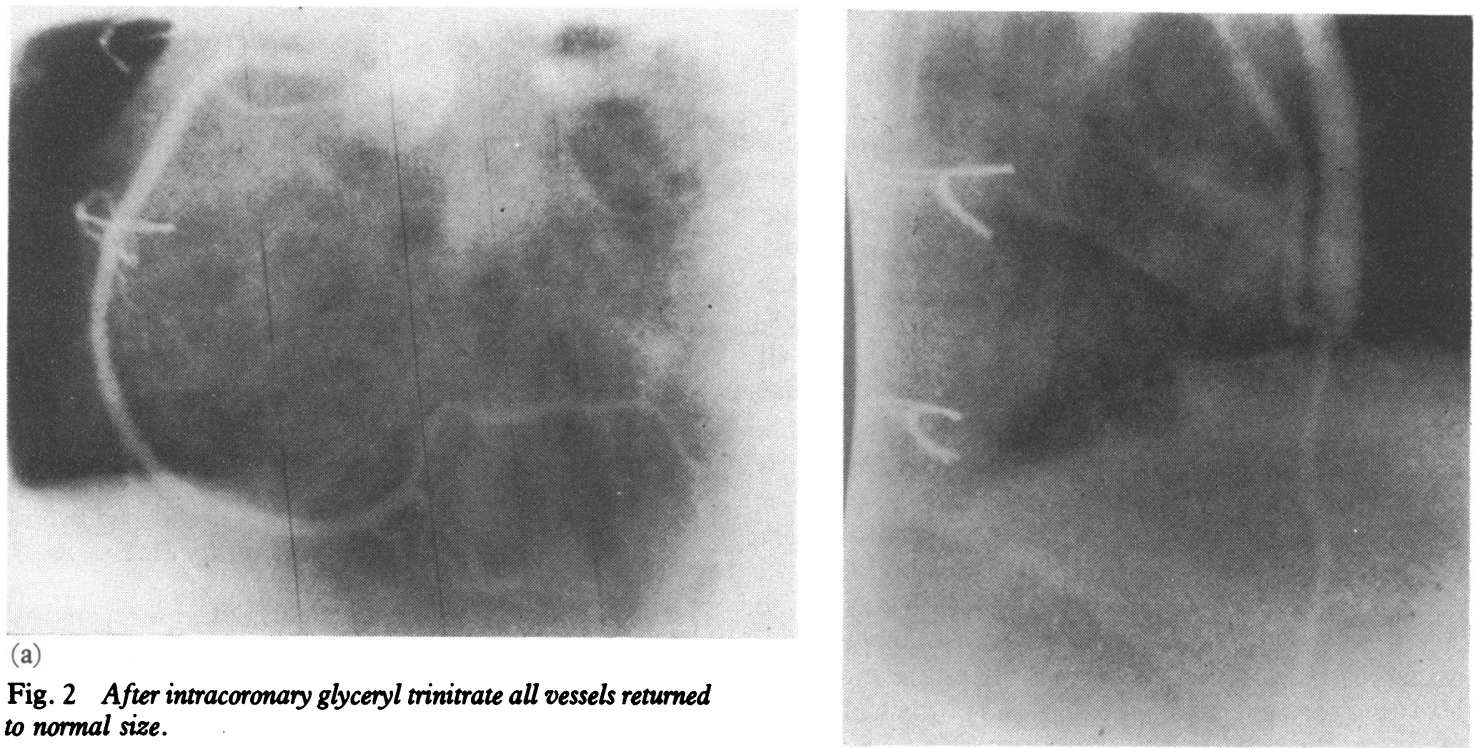

(b)

\section{Discussion}

The appearance of signs of perioperative myocardial infarction in the area of stenosed, grafted vessels has long been regarded as paradoxical. ${ }^{278}$ This upsetting and occasionally fatal complication has become rare in recent years, ${ }^{3}$ probably because of the wide adoption of cardioplegic techniques and the improvements in surgical skills. ${ }^{3}$

Perioperative myocardial infarction in areas distal to normal vessels may constitute an entirely different problem. Bolooki et al. ${ }^{9}$ reported one case of anterior wall infarction with patent left anterior descending artery after right coronary artery bypass grafting. Assad-Morell et al. ${ }^{10}$ reported three cases and Bulkley et al. ${ }^{7}$ reported one case, with a normal dominant right coronary artery, patent vein graft(s) to the left coronary system, and perioperative infarction of the 
diaphragmatic wall of the heart. No interpretation was offered, and it remained for Pichard et al. ${ }^{11}$ to suggest that coronary artery spasm might be responsible for postoperative ischaemic events. Buxton et al. ${ }^{4}$ recently provided angiographic proof of this hypothesis in one case, and reported five more cases with less direct, yet highly suggestive, evidence of the same phenomenon.

Although perioperative "functional" obstruction of the coronary arteries may occur in any vessel, it has been more frequently seen in patients with normal right coronary arteries, which have not been bypassed. ${ }^{4512}$ Patency of the right coronary artery thus seems to be a factor in this condition, as does a history of angina at rest. ${ }^{46}$ The relations with variant angina are certainly intriguing, but have not been completely elucidated. Recent reports on this subject, however, do not substantiate the hypothesis of a significantly increased risk of perioperative spasm in patients with this syndrome. ${ }^{13-15}$

All six patients reported by Buxton et al. ${ }^{4}$ presented with sudden hypotension and arrhythmias within two hours of termination of cardiopulmonary bypass; two other reports describe a similar sequence of events ${ }^{612}$ which was also seen in three additional patients in our unit in whom no angiographic proof of the coronary spasm was obtained. This mode of presentation, when associated with significant ST segment elevation, may be regarded as typical of acute postoperative coronary spasm, and particularly so when the preoperative angiograms showed that the involved vessel was not diseased. The case presented here illustrates a wider spectrum of possibilities for perioperative coronary spasm; not only may a diseased, grafted vessel be involved, 611 but also all coronary arteries may simultaneously undergo diffuse spasm.

The relevance of this perculiar complication is threefold. First, it may affect patients with single or double vessel disease undergoing what usually appear to be simpler surgical procedures at negligible risk. Second, it may evolve in an unfavourable way in the surgical setting, since it is resistent to conventional drug treatment. Third, its correct identification may lead to effective management: that is direct injection of drugs into the spastic coronary artery, either at operation or in the catheterisation laboratory, associated with administration of nitrates and/or calcium antagonists intravenously or sublingually ${ }^{6}$

We conclude therefore that the possibility of coronary spasm should be promptly considered when analysing perioperative ischaemic events. An aggressive diagnostic and therapeutic approach is warranted in view of the poor prognosis.

The cooperation of Professor Fulvio Camerini and Dr
Silvio Klugmann, from the Department of Cardiology, in the management of our case and with the preparation of this report is acknowledged.

\section{References}

1 Brewer DL, Bilbro RH, Bartel AG. Myocardial infarction as a complication of coronary bypass surgery. Circulation 1973; 47: $58-64$.

2 Langou RA, Wiles JC, Peduzzi PN, Hammond GL, Cohen LS. Incidence and mortality of perioperative myocardial infarction in patients undergoing coronary artery bypass grafting. Circulation 1977; 56, suppl 2: 54-8.

3 Burton JR, FitzGibbon GM, Keon WJ, Leach AJ. Perioperative myocardial infarction complicating coronary bypass: clinical and angiographic correlations and prognosis. F Thorac Cardiovasc Surg 1981; 82: 758-64.

4 Buxton AE, Goldberg S, Harken A, Hirshfeld J Jr, Kas- 근 tor JA. Coronary-artery spasm immediately after myocardial revascularization. $N$ Engl f Med 1981; 304: $1249-53$.

5 Ginsburg R, Stinson EB, Bristow MR, Schroeder JS. Coronary artery spasm after revascularization (Letter). N Engl f Med 1981; 305: 699.

6 Lewis BH, Muller JE, Rutherford J, Mudge GH Jr, Collins J J Jr. Nifedipine for coronary-artery spasm after revascularization (Letter). $N$ Engl $\mathcal{F}$ Med 1982; 306: 992-3.

7 Bulkley BH, Hutchins GM. Myocardial consequences of coronary artery bypass graft surgery: the paradox of nec- $₫$ rosis in areas of revascularization. Circulation 1977; 56: $\overrightarrow{\vec{B}}$ 906-13.

8 Codd JE, Sullivan RG, Weins RD, Barner HB, Kaiser GC, Willman VL. Myocardial injury following myocardial revascularization. Detection by isoenzyme analysis. Circulation 1977; 56, suppl 2: 49-53.

9 Bolooki H, Sommer LS, Ghahramani A, Cunha D. ํํㄹ Complications of coronary bypass surgery. Circulation 1973; 48: suppl 3: 120-6.

10 Assad-Morell JL, Frye RL, Connolly DC, et al. Relation of intraoperative or early postoperative transmural $\frac{0}{3}$ myocardial infarction to patency of aortocoronary bypass grafts and to diseased ungrafted coronary arteries. $A m \mathcal{F}$ 윽 Cardiol 1975; 35: 767-73.

11 Pichard AD, Ambrose J, Mindich B, et al. Coronary artery spasm and perioperative cardiac arrest. F Thorac N
Cardiovasc Surg 1980; 80: 249-54.

12 Zeff RH, Iannone LA, Kongrahworn C, et al. Coronary N artery spasm following coronary artery revascularization. N Ann Thorac Surg 1982; 34: 196-200.

13 Russell RO Jr, Moraski RE, Kouchoukos N, et al. Unstable angina pectoris: National cooperative study group to읃 compare surgical and medical therapy. III. Results in patients with S-T segment elevation during pain. $A m \mathcal{F}^{\mathscr{C}}$ Cardiol 1980; 45: 819-24.

14 Johnson AD, Stroud HA, Vieweg WVR, Ross J Jr. Var-움 iant angina pectoris. Clinical presentations, coronary angiographic patterns, and the results of medical and尽 surgical management in 42 consecutive patients. Chest $\frac{\varrho}{\sigma}$ 1978; 73: 786-94. 
15 Pasternak RC, Hutter AM Jr, DeSanctis RW, JaRo MF, Buckley MJ. Variant angina: clinical spectrum and results of medical and surgical therapy. $\mathcal{f}$ Thorac Cardiovasc Surg 1979; 78: 614-22.
Requests for reprints to Dr Bartolo Zingone, Vicolo degli Scaglioni 22, Trieste, Italy.

British Cardiac Society

The Annual General Meeting for 1983 will take place in Bristol on 13 and 14 April, and the closing date for abstracts was 4 January 1983.

The Autumn Meeting will be held at Wembley on 21 and 22 November 1983, and the closing date for abstracts will be 28 July 1983. 